\title{
A Simple, Rapid Analysis, Portable, Low-cost, and Arduino-based Spectrophotometer with White LED as a Light Source for Analyzing Solution Concentration
}

\author{
Asep Bayu Dani Nandiyanto*1, Rena Zaen ${ }^{2}$, Rosi Oktiani ${ }^{3}$, Ade Gafar Abdullah ${ }^{4}$, \\ Lala Septem Riza ${ }^{5}$ \\ ${ }^{1,2,3}$ Department Kimia, Universitas Pendidikan Indonesia, Bandung, Indonesia \\ ${ }^{4}$ Department Teknik Elektro, Universitas Pendidikan Indonesia, Bandung, Indonesia \\ ${ }^{5}$ Department IImu Komputer, Universitas Pendidikan Indonesia, Bandung, Indonesia \\ ${ }^{*}$ Corresponding author, e-mail: nandiyanto@upi.edu
}

\begin{abstract}
The purpose of this study was to demonstrate a simple, rapid analysis, portable, and inexpensive spectrophotometer. Different from other spectrophotometers, the present instrument consisted of a single white light-emmiting-diode (LED) as a light source, a light sensor, and arduino electronic card as an acquisition system. To maintain a constant light intensity, a common white-color LED emitting a 450-620 $\mathrm{nm}$ continous spectrum was employed. Software was written in $\mathrm{C}++$ to control photometer through a USB interface and for data acquistion to the computer. The instrument is designed to be simple and compacted with sizes of $200 \times 130 \times 150 \mathrm{~mm}$ for length, width, and height, respectively. The analysis of the total cost isaboutless than 500 USD, while commercially available offers price of more than 10,000 USD. Thus, this makes the present instrument feasible for teaching support media in developing countries. The effectiveness of the present spectrophotometer for analyzing solution concentration (i.e. curcumin) was also demonstrated. Interestingly, the present spectrophotometer is able to measure the concentration of curcumin precisely with an accuracy of more than $90 \%$. Different from commercially available standard $U V$-visible spectrophotometers that have limitations in the analysis of concentration of less than 50 ppm, the presentsystem can measure the concentration with no limitation since the measurement is based on the LED light being penetrated.
\end{abstract}

Keywords: lightemitting diode; spectrophotometer; curcumin; concentration analysis; arduino

Copyright $@ 2018$ Universitas Ahmad Dahlan. All rights reserved.

\section{Introduction}

In the seventies of the last century, Flaschka et al [1] reported development of lightemitting diode (LED)-based photometers. Their method is prospective to generate further developed and sophisticated photometers, which can be found in many commercially available analytical instruments and characterization equipments. Although current available instruments and equipments are effective to measure many characterization analyses, the quality of the analysis is directly dependant on increases in cost and complexity of the optical and electronic system. Indeed, this meets problems, especially when applying the instrument for educational purposes in developing countries. This becomes the main reason for the increasing demand for simple, portable, and inexpensive chemical analyses.

To meet this demand, many scientists have reported the development of simple instruments. For example, Shimazaki et al [2] and Veras et al [3] reported the use a white LEDbased spectrophotometer for analyzing iron ion in aqueous solution. De Morais et al [4] reported the design of photometer for the analysis of lead ions. Other developed instruments were reported by $\mathrm{Li}$ et al [5] that presented a portable multi-function instrument using LED-based different spectrophotometric techniques for analyzing chromium and aluminium ions. Other paper is then reported by Kittipanyangam et al [6]. They compared the use of LED with different color intensities, i.e. red, green, and blue. Although current methods as described above are effective for analyzing concentration of the solution, problems still persisted. Current designed instruments must be supported by sophisticated design and some specific apparatuses. Further, their methods seemed to be inconvenient especially for researchers that have no background 
on the electrical science and engineering. In fact, the idea in the above demand is mainly for educational purposes in school.

In our previous studies, we have already worked with the concentration analysis [7-10]. All analyses are typically employed and can not be separated with the spectrophotometer. Indeed, this analysis is typically common in high technology research, while this typical analysis in the school is hard to be implemented.

Therefore, the purpose of this study was to introduce a simple, rapid analysis, portable, and low-cost spectrophotometer. This spectrophotometer has been applied in our previous studies $[7,8,10]$, but we did not discuss in detail how the instruments work.

The prepared instrument is one of the proposed solutions on how to solve current problems for the demand in the spectrophotometer for school. To simplify the development of the instrument, the proposed photometer is Arduino-based spectrophotometer with white LED as a light source. Ardunio is used as an acquistion system due to its well-known system and user friendly, making the non-electrical background users being able to put into practice [11]. That is the main reason why the arduino has been used in various applications [11-14]. The effectiveness of the present spectrophotometer for analyzing solution concentration (i.e. curcumin) was also demonstrated.

Experimental results showed that the present spectrophotometer is able to measure the concentration of curcumin precisely with an accuracy of more than $90 \%$. Different from commercially available standard UV-visible spectrophotometers that have limitations in the analysis of concentration of less than $50 \mathrm{ppm}$, the present system can measure the concentration with no limitation as long as the LED light beingtransmitted. Economic analysis of the total cost showed that the present instrument is relatively inexpensive and possible to be implemented for teaching supporting media in developing countries.

\section{Experimental Method}

\subsection{Design Portable Spectrophotometer}

Figure 1 shows a schematic illustration of the present portable spectrophotometer. The system contains a white-color LED light source (10 W; emitting a 450-620 nm continous spectrum), glass cuvette cell $(12.5 \times 12.5 \times 45 \mathrm{~mm})$, and a photosensor. Regarding the photosensor, a light sensor (lux meter; BH1750FVI, Rohm Co. Ltd., Japan) was used and equipped with arduino system (arduinoUNO). All components were constructed within an acrylic case, whose size was $200 \times 130 \times 150 \mathrm{~mm}$ for length, width, and height, respectively. Total mass of the present spectrophotometer was about $1 \mathrm{~kg}$.

To ensure the analysis result be obtained precisely and real time, the system was set and programmed for being able to connect with computer. In short, the arduino system was equiped with software using the Arduino IDE 1.0.6. The software was written in $\mathrm{C}++$ to control photometric analysis through a USB interface and for data acquistion to the computer.

\subsection{Implementation of Spectrophotometer for Analyzing the Concentration of Curcumin Preparation of Curcumin}

To demonstrate the effectiveness of the present spectrophotometer on measuring the concentration of solution, the analysis of various curcumin concentrations was conducted. In short, to get the extracted curcumin, a piece of turmeric (purchased from local market in Bandung, Indonesia) was washed, sliced into small pieces (sizes of about $1 \times 1 \mathrm{~cm}$ ), and dried at $70^{\circ} \mathrm{C}$ (to remove the water content in the turmeric). Next, the dried turmeric was grinded and dissolved into water. The turmeric suspension was then filtered to get curcumin solution. The concentration of curcumin solution was fixed at $100 \mathrm{ppm}$. For being used for variation of curcumin concentration, the $100 \mathrm{ppm}$ of curcumin was diluted by aqueous solution. Detailed information regarding the extraction of curcumin is explained in our previous reports $[8,9]$. In addition, to ensure the successful isolation of curcumin from turmeric, several characterizations were conducted, including a Fourier Transform Infra Red (FTIR; Prestige 21, Shimadzu Corp., Japan)) for analyzing the chemical composition in the sample.

\subsection{Measurement Procedure}

The demonstration of the spectrophotometer measurement was conducted by putting about $3 \mathrm{~mL}$ of aliquot curcumin with a specific concentration. The measurement result was then 
compared to that gained from standard procedure using a standard UV-Visible spectrophotometer (UV-Vis mini 1240, Shimadzu Corp., Japan).

For obtaining the results of the present spectrophotometer, the Beer Lambert Law is typically used. The law correlates absorbance $(A)$ with molar absorptivity $(\varepsilon, \mathrm{L} / \mathrm{mol} . \mathrm{cm})$, path length of light in the sample $(b ; \mathrm{cm})$, and concentration $(C ; \mathrm{mol} / \mathrm{L})$. The correlation can be written as [15].

$$
A=\varepsilon . b . C
$$

Then, when the above correlation involves the light transmittance $(T)$ and light intensity $(I)$, the absorption $A$ is defined as [15]

$$
A=-\log (T)=\log \left(\frac{I}{I o}\right)
$$

where 10 is the initial light intensity.

Similar to the above measuring procedure for the present photometer, the analysis of curcumin concentrations using the standard UV-Visible spectrophotometer used Beer-lambert law at a wavelength of $425 \mathrm{~nm}$. The implementation of above equation can be redefined into [7-8], [10]

$$
\frac{C t}{C o}=\frac{A t}{A o}
$$

where $\mathrm{Co}$ and $\mathrm{Ct}$ are the concentration of curcumin at the initial time and that at the measured time, respectively. Ao and $A t$ are the absorption peak at the initial time and that at the measured time, respectively.

In addition, to ensure the precision in the measurement analysis, each measurement was conducted more three times, in which the average data (instead of anomaly data) was taken as the result.

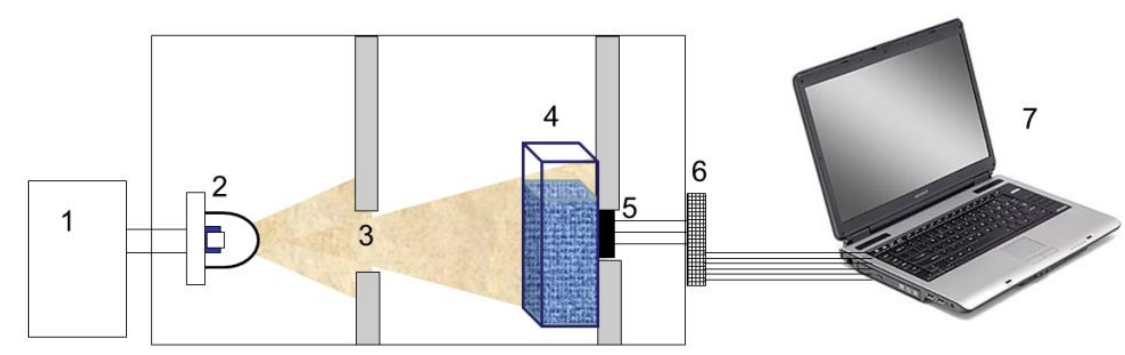

Figure 1. Schematic diagram of portable LED-based spectrophotometer. Components including in the photometer system are (1) LED driver, which connect to the power supply, (2) LED lamp,

(3) hole for focusing light beam, (4) cuvette with measured solution, (5) luxmeter as the light intensity sensor, (6) arduino and (7) computer

\section{Results and Discussion}

\subsection{Isolation of Curcumin from Turmeric}

The performance of the present spectrophotometer was validated using a curcumin solution. Prior to measuring the curcumin solution, the curcumin solution was analyzed using several characterization analyses as shown in Figures 2-3.

Figure 2 shows the FTIR analysis results of the curcumin solution. The result detected several peaks in the sample. A sharp peak in $3425 \mathrm{~cm}^{-1}$ indicated a strong $\mathrm{O}-\mathrm{H}$ stretching, confirming the possibility of curcumin for dissolving in aqueous solution. In addition to $\mathrm{OH}$ related peak, several peaks were identified, which are classified as specific spectra of curcumin (shown in the dashed area) such as 1438 (olefinic $\mathrm{C}-\mathrm{H}$ bending vibration), $1510 \quad(\mathrm{C}=\mathrm{C}$ 
vibrations), as well as 1597 and $1674 \mathrm{~cm}^{-1}$ (C-O stretch). The appearance of these peaks verified the successful isolation of curcumin from turmeric. The present peaks regarding the curcumin peaks are in a good agreement with other reports [8-9].

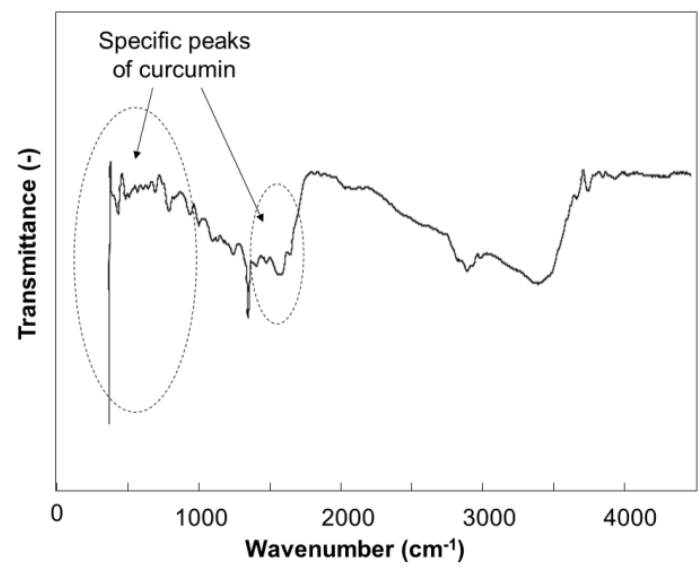

Figure 2. FTIR analysis of the curcumin solution

Figure 3 shows the analysis results gained from the standard UV-Visible spectrophotometer with photograph images of curcumin samples with various concentrations. Various concentrations of curcumin from 0 to $100 \mathrm{ppm}$ were tested. As shown in the paneled photograph image, the concentration of curcumin relates directly to the color and turbidity. As a consequence, different absorption patterns were detected, depending on the concentration of curcumin. Based on the UV-Vis spectrum curves, the main peaks were detected at the wavelength of about $280 \mathrm{~nm}$ for all cases, confirming the yellow color.

The absorbance at all wavelengths decreased with the decreases in the concentration, confirming that the higher concentration of curcumin correlates to the more lights being absorbed. The absorption process is in a good agreement with change in visual observation that the higher concentration results in the solution to have more turbid yellow color as shown panelled photograph image in Figure 3). The present correlation between the concentration and the absorbance is in a good agreement with other reports $[7,10]$.

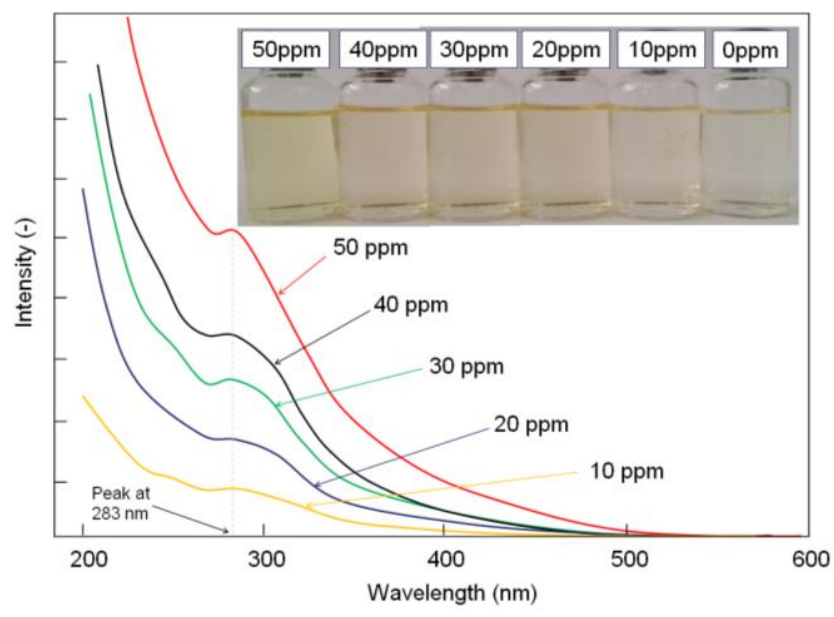

Figure 3. Standard UV-Vis spectrophotometer analysis results. The panelled figure is the photograph images of curcumin samples with various concentrations 


\subsection{Performance Evaluation of the Present Spectrophotometer}

The optical system is composed by a white LED supported with focus hole to create a small light beam (2 cm in diameter) in front of the light sensor (See Figure 1). This hole is to promote the focus of the light beam. To minimize the interference of other light to the sensor measurement (especially light reflection from outside the spectrophotometer device), both inside and outside of the case were coated with black color.

To increase the spectral resolution, the position of the sensor was put directly behind the glass cuvette cell. Thus, the sensor detects the light only which is from the penetration through the liquid solution. Therefore, when high turbidity of solution is put into the glass cuvette cell, the sensor detects low intensity due to less transmission of light through the solution.

Interestingly, this system is relatively faster and more accurate compared to the standard UV Visible spectrophotometer. Further, since the standard UV-Visible spectrophotometer must scan all light wavelengths that make the measurement will be timeconsuming, the present photometer detects in the specific wavelength. The white LED is used since this type of light contains the specific wavelength that is compatible to the sensor.

Table 1 shows the comparison results of curcumin measurement using the present spectrophotometer and standard UV-vis spectrophotometer. The calibration of the both measurement analyses were conducted in the concentration of curcumin that from 0 to 100 $\mathrm{ppm}$. Curcumin was tested until $100 \mathrm{ppm}$ since this concentration is the maximum solubility of curcumin in aqueous solution. Thus, increases in more concentration of curcumin will need additional chemical solvent such as alcohol. Indeed, additional other chemical will generate additional factor in the measurement system.

Both methods are effective to measure the concentration of curcumin. Interestingly, the result showed that the standard spectrophotometer is effective for measuring the concentration of curcumin of between 0 to $50 \mathrm{ppm}$, whereas the present portable system is possible for analyzing solution with no limitation.

Table 1. Comparison of analysis results between the present spectrophotometer and the standard UV-Visible spectrophotometer. The analyses were conducted by measuring the

\begin{tabular}{|c|c|c|c|c|}
\hline \multirow{2}{*}{$\begin{array}{c}\text { Curcumin } \\
\text { sample (ppm) }\end{array}$} & \multicolumn{2}{|c|}{$\begin{array}{l}\text { The present portable } \\
\text { spectrophotometer }\end{array}$} & \multicolumn{2}{|c|}{$\begin{array}{l}\text { Standard UV-Visible } \\
\text { spectrophotometer }\end{array}$} \\
\hline & Result (ppm) & Error (\%) & Result (ppm) & Error (\%) \\
\hline 0 & -6.60 & 1.14 & 0 & 0 \\
\hline 10 & 7.12 & 28.77 & 9.14 & 8.53 \\
\hline 20 & 20.08 & 0.40 & 19.24 & 3.78 \\
\hline 30 & 32.43 & 8.12 & 29.50 & 1.68 \\
\hline 40 & 43.90 & 9.76 & 39.55 & 1.13 \\
\hline 50 & 52.92 & 5.84 & 50 & 0 \\
\hline 60 & 76.94 & 28.24 & - & - \\
\hline 70 & 66.92 & 4.40 & - & - \\
\hline 80 & 68.85 & 13.93 & - & - \\
\hline 90 & 89.26 & 0.83 & - & - \\
\hline 100 & 98.03 & 1.97 & - & - \\
\hline
\end{tabular}

Based on the above analysis result, although for some cases the present spectrophotometer has higher error value than the standard UV Vis spectrophotometer, the present device is prospective for being used in educational purposes in underdeveloped and developing countries. This is because the total cost for designing instruments is less than 500 USD, while the standard UV-Visible spectrophotometer needs at least 10.000 USD. Further, the present device is effective for analyzing even high-turbidity solution, making this instrument reliable for various uses.

\section{Conclusion}

The present study has demonstrated how to measure concentration of solution (i.e. curcumin) using a simple, rapid analysis, portable, and inexpensive spectrophotometer. The proposed photometer is Arduino-based spectrophotometer with white LED as a light source. The result showed that the present spectrophotometer is able to measure the concentration of 
curcumin precisely with an accuracy of more than $90 \%$. Different from commercially available standard UV-visible spectrophotometer that has limitation in the analysis of concentration of less than $50 \mathrm{ppm}$, the present system can measure the concentration without no limitation since the measurement is based on the LED light being penetrated.

\section{Acknowledgements}

Authors acknowledged RISTEKDIKTI for supporting this research using grant Penelitian Produk Terapan (PPT).

\section{References}

[1] Flaschka H, McKeithan C, Barnes R. Light Emitting Diodes and Phototransistors in Photometric Modules. Analytical Letters. 1973; 6(7):585-594.

[2] Shimazaki Y, Watanabe S, Takahashi M, Iwatsuki M. A Portable Spectrophotometer Using a WhiteColor Light-emitting Diode and a Charge-coupled Device and Its Application to on-site Determination of Iron. Analytical Sciences. 2000; 16(10): 1091-1093.

[3] Veras G, Silva EC, Lyra WS, Soares SFC, Guerreiro TB, Santos SRB. A Portable, Inexpensive and Microcontrolled Spectrophotometer Based on White LED as Light Source and CD Media as Diffraction Grid. Talanta. 2009; 77(3): 1155-1159.

[4] de Morais CDL, Carvalho JC, Sant'Anna C, Eugênio M, Gasparotto LH, Lima KM. A Low-cost Microcontrolled Photometer with One Color Recognition Sensor for Selective Detection of Pb 2+ Using Gold Nanoparticles. Analytical Methods. 2015; 7(18): 7917-7922.

[5] Li Q, Morris KJ, Dasgupta PK, Raimundo IM, Temkin H. Portable Flow-injection Analyzer with LiquidCore Waveguide Based Fluorescence, luminescence, and long path length absorbance detector. Analytica Chimica Acta. 2003; 479(2): 151-165.

[6] Kittipanyangam S, Do W, Abe K, Eguchi K. Design of a Hand-Made Light Absorbance Measurement Device for Chemical Education. International Journal of Innovative Computing Imformation and Control. 2016; 12(5): 1397-1410.

[7] Nandiyanto ABD, Sofiani D, Permatasari N, Sucahya TN, Wiryani AS, Purnamasari A, Rusli A, Prima EC. Photodecomposition profile of organic material during the partial solar eclipse of 9 march 2016 and its correlation with organic material concentration and photocatalyst amount. Indonesian Journal of Science and Technology. 2016; 1(2): 132-155.

[8] Nandiyanto ABD, Wiryani AS, Rusli A, Purnamasari A, Abdullah AG, Riza LS. Decomposition Behavior of Curcumin during Solar Irradiation when Contact with Inorganic Particles. IOP Conference Series: Materials Science and Engineering. 2017; 180(1): 012135.

[9] Nandiyanto ABD, Wiryani AS, Rusli A, Purnamasari A, Abdullah AG, Widiaty I, Hurriyati R. Extraction of Curcumin Pigment from Indonesian Local Turmeric with Its Infrared Spectra and Thermal Decomposition Properties. IOP Conference Series: Materials Science and Engineering . 2017; 180(1): 012136.

[10] Nandiyanto ABD, Zaen R, Oktiani R. Correlation between crystallite size and photocatalytic performance of micrometer-sized monoclinic WO3 particles. Arabian Journal of Chemistry. in press.

[11] Jidin AZ, Yusof NM, Sutikno T. Arduino Based Paperless Queue Management System. TELKOMNIKA (Telecommunication Computing Electronics and Control). 2016; 14(3): 839-845.

[12] Ibrahim MNR, Solahudin M, Widodo S. Control System for Nutrient Solution of Nutrient Film Technique Using Fuzzy Logic. TELKOMNIKA (Telecommunication Computing Electronics and Control). 2015; 13(4): 1281-1288.

[13] Jusoh A, Alik R, Guan TK, Sutikno T. MPPT for PV System Based on Variable Step Size P\&O Algorithm. TELKOMNIKA (Telecommunication Computing Electronics and Control). 2017; 15(1): 7992

[14] Koprda Š, Magdin M. Implementation of Innovative Technologies in the Fields of Electronic Locks. TELKOMNIKA (Telecommunication Computing Electronics and Control). 2016; 14(4): 1329-1337.

[15] David M, Ibrahim MH, Idrus SM, Marcus TCE. Fundamental Review to Ozone Gas Sensing Using Optical Fibre Sensors. TELKOMNIKA (Telecommunication Computing Electronics and Control). 2015; 13(4): 1133-1144. 